\title{
Prognosis-based medicine-The importance of psychosocial factors: Conceptualization from a case of acute pericarditis
}

\author{
Jose Luis Turabian* \\ Specialist in Family and Community Medicine, Health Center Santa Maria de Benquerencia. Regional Health Service of Castilla la Mancha (SESCAM), Toledo, Spain
}

\begin{abstract}
Prognosis is a fundamental component of general medicine, however, research and reflection on the concept of prognosis is currently neglected, there is a lack of knowledge about how the pronostic process is made by medical experts, and there being no clear consensus on its systematization in practice, teaching and evaluation. A clinical case of acute pericarditis is presented, and some elements are induced about conceptual characteristics of the prognosis applicable to family medicine. It has been said the prediction about the evolution of a patient and the final result of the disease can only be done reliably through a statistical study that associates the prognosis with certain symptoms or clinical signs, but a clinical history is at the same time a story of a lifetime. The illness is unique for each individual, and so the prognosis can be seen as a science and an art: one can be objective in that subjective part of "art" through contextualization and individualization. Patient prognosis is determined by more than disease diagnosis. Prognosis can be highly variable in persons with a same particular diagnosis. There are different prognoses of the same symptom or disease according to contexts. The prognosis of diseases depends more on psychosocial factors that of biomedical factors. Given the fundamental importance of the prognosis in medical practice, it is recommended to move from a diagnosis-based medicine to one based on prognosis.
\end{abstract}

\section{Introduction}

The conventional clinical approach implies to establish a diagnosis, a prognosis and a treatment. "Prognosis" is the forecast of the probable outcome or course of a disease; the patient's chance of 'recover. Diagnosis has been considered as the main guideline for treatment and is considered the central component of clinical practice; but prognosis, which refers to the possible outcomes of a disease and the frequency with which they can be expected to occur, is an essential element of health care decision making is related to "what is going to happen next" [1-3].

Prognosis is the judgment of a health professional about the changes that may occur in the course of an illness, and it anticipates its possible result in the patient. The prognosis of the disease is obtained by evaluating all the signs and symptoms that a patient presents, as well as their context, in addition to the information that comes from the complementary tests, such as the physical examination and the clinical analyzes, with the objective of estimating a diagnosis, the patient's condition and the most effective treatment for each determined case.

The concept of prognosis dates to antiquity [4]. Hippocrates was the first doctor who treated in a detailed and profound way the prognosis of the patients he attended. One of the most important parts of the Hippocratic Collection speaks extensively on this subject, granting great importance to the prognosis, of which it said: "It seems to me that the best thing the doctor can do is to worry about the ability to foresee", adding that: "The doctor can predict the evolution of a disease by observing a sufficient number of cases."

The opinions of Hippocrates expressed the views of the School of Cos, which gave greater importance to the prognosis, contrary to its neighbours of the Cnido School, which granted more relevance to the diagnosis. With the development of medicine, the systematization and classification of diseases into groups and types became very important, and the concern for diagnosis exceeded that given to the prognosis, with the argument that when the diagnosis was made, the prognosis was made automatically [5]. In the past, the lack of effective diagnostic or therapeutic methods made prognosis the most important part of medical practice. Not yet long ago, the success of the doctor was valued, in large part, by the success achieved in the prognosis $[5,6]$.

Although prognosis is considered a fundamental component of general medicine, it is a skill that is currently neglected, and even prognostic refection tends to disappear from textbooks and from training programs, but family physicians must be equipped with the relevant skills to form prognoses for their patient [4-7].

The uncertainty in the family medicine consultation increases the difficulty in making the prognosis. In addition, when the doctor faces a situation of great uncertainty, especially combined with time constraints, he usually resorts to requesting more tests, which inevitably leads to increased costs of care [8].

On the other hand, although the diagnosis is the current basis for decision-making in clinical practice, this central role is opposed to the evidence that patients are not always benefited from it, as there are other factors besides biomedical disease which are important for the patient's outcome. In this way, it has been proposed that a clinical practice model focused on the patient's prognosis and results may be more useful. The patient's prognosis could be the framework in which clinical practice integrates biological and social information for better

${ }^{\star}$ Correspondence to: Jose Luis Turabian, Specialist in Family and Community Medicine, Health Center Santa Maria de Benquerencia. Regional Health Service of Castilla la Mancha (SESCAM), Toledo, Spain, Tel: +34925154508; Email: jturabianf@hotmail.com

Key words: evidence-based medicine, prognosis, medical decision-making, diagnosis, outcomes of care, prediction, biopsychosocial

Received: March 04, 2018; Accepted: March 16, 2018; Published: March 19, 2018 
care. However, the reality is that there is a lack of knowledge about the prognosis process in medical experts, and there is no clear consensus on its systematization in practice, teaching and evaluation [1].

Physicians should always be attentive to opportunities to reflect on their practice, as one of the main methods of learning and professional and personal development. An important role of the daily work of the General Practitioners (GPs), is to look at real life in front of the life taken from a "book" or a "film". What most interests the GPs conceptually is the part of life that exists in the disease, and that is little systematized, remembered or studied; they are questions that are not usually asked. Symptoms in family medicine are not symptoms of illness, but "symptoms of life"; in the consultation "he enters, together with the patient, all his life". Thus, any query is primarily a bio-psycho-social problem (BPS): The individual in relation to his ego and its context [9]. And all this has important implications in the establishment of the prognosis of the patient's disease.

In this scenario, a clinical case of viral pericarditis or idiopathic acute pericarditis is presented, and we are thinking about its prognosis that affects the indicated time of rest in a young patient, who is finally is discovered that he is an athlete, and from these elements are induced some conceptual characteristics about the prognosis applicable to family medicine.

\section{Clinical Observation}

A previously healthy 35 -years-old man, ex-smoker for 5 months, with no other known antecedents, presents with pleuritic intermittent chest pain of an oppressive nature that yields with rest, of several hour's duration. His pulse was 55 beats per minute and regular, his blood pressure was $125 / 80 \mathrm{~mm} \mathrm{Hg}$ without a paradoxical pulse, and his temperature was $37.8^{\circ} \mathrm{C}$. An electrocardiogram (ECG) reveals elevation of the ST in the inferior face and from V3 to V6 and decrease in the PR in AVR. Enzymatic seriation is negative. Echocardiogram is normal. General analytics is normal. RX of thorax is normal. Acute pericarditis is diagnosed and acetylsalicylic acid $1 \mathrm{~g}$ is prescribed every 6 hours. Twenty days later he is asymptomatic.

In this way, it can be considered that the patient is adequately treated from the biological point of view. He visited to the GP weekly, and in those consultations, he seemed restless or nervous and used to express his wish to can back on the job-with a low voice, as if he were undecided or doubtful, and with a half-smile that seemed to show insecurity. The GP recommended him to maintain rest and sick leave, accepting the established guidelines of the prognosis and resting time of acute pericarditis. After a month and a half, the patient asks the doctor: "Could I run slowly?" At that moment, the GP realizes that the patient raises his fundamental concern, which is to return to sports activities; this was a subject that had been forgotten by the GP and about which it had not been investigated; The GP did not know that the patient was an athlete, and that this aspect was central to his life (Table 1).

\section{Discussion}

\section{The prognosis is fundamental for the practice of general medicine}

The prognosis is a fundamental requirement to be able to make correct therapeutic decisions [10,11]. Of course, the diagnosis of the disease is a basic component of medicine, but it does not provide a sufficiently big framework to make useful decisions, which must incorporate the variability in the patient's individual risk, that goes far beyond biomedical disease; so, the prognosis can provide the general practitioner with such a framework for future decisions [1].

The prognosis is the forecast of the evolution, the character of the development and the end of the disease, based on the knowledge of the regularities of the course of the pathological processes. Prognosis refers to the results of a disease and how often it is expected to occur. It is an inherent concern of the clinic. In medical practice the exercise of predicting the future course of a disease, its results and its frequency is a constant work. This prognosis can be important for the decision to treat a patient and how to treat it, reduce their anxiety, as well as promote certain behaviors in the people we serve [6]. Thus, in the clinical case presented, the prognosis and the consequent decision of the resting time was the most important element for the patient.

Many are the factors depending on the disease, such as its severity and extent, the involvement of vitally important organs, the degree of disorder in the organic functions and the possibility of reversibility of the functional and morphological changes of the organism, the frequency and severity of its complications and the duration of the disease, which greatly influence the prognosis, and should be known and evaluated. Other factors that depend on the patient, such as age, sex, previous health status, the diseases they suffer, the inheritance, the cultural level, the disposition and possibilities of cooperating with the treatment, and the physical and mental state are also very important in the forecast. The temperament and character of the patient are also essential for the prognosis of the course of the disease and the ability to work after convalescence. Some patients become disabled because of insignificant disorders, and others fight valiantly against their illness and have an active lifestyle [6].

\section{The example of acute pericarditis}

Pericarditis is an important diagnosis to consider in a patient with chest pain. It is diagnosed in $5 \%$ of patients who come to hospital emergency departments for chest pain in the absence of a myocardial infarction $[12,13]$. In the daily practice of general practitioners, questions may arise to advice on exercise programs and sports participation in young individuals with cardiovascular diseases. Physical exercise has an important role in the leisure time of our society. Many patients with heart disease do not want to give up their physical activity or sports programs. On the other hand, there is no doubt that many of the cardiovascular abnormalities can benefit from a program of controlled physical exercise [14].

Table 1. A case of acute pericarditis; the case of George: The biopsycosocial or contextualized prognosis and the biomedical prognosis. 
On the other hand, there are numerous examples of diseases where the biological data, considered in isolation, have little relevance for the individual prognosis; thus, for example, in myocarditis, endomyocardial biopsy is considered as the gold standard, but none of the endomyocardial biopsy-derived parameters have been significantly associated with return to work in patients; therefore, added to established predictors, bioptic data demonstrated no additional impact for return to work probability. In consequence, socio-medical evaluation of patients remains an individually oriented process based on clinical, functional and contextual parameters [15].

There are many clinical guidelines written by experts in their fields that can help practical doctors make decisions about returning to physical activity for athletes with known or suspected heart conditions [16]. However, the indicated rest time in an athlete with pericarditis is a matter not fully clarified in the medical literature, and the therapeutic approach varies widely, from advising a minimum of 6 months of rest from the documentation of the cure; going through bed rest 2 weeks; rest in bed or chair while pain and fever persist; or returning to full activity when there is evidence that the disease is not active, including absence of effusion by echocardiography, and when the serum markers of inflammation have normalized [17-23] (Table 2).

\section{A clinical history is at the same time a story of a lifetime}

Clinical disease is the story of a whole life (the problems, the longings, the failures, the successes, the efforts ..., aggravations or improvements ...). It has been known on diaphanous clarity that the disease course and prognosis depends on the patient personality and his situation. The workers with heavy work, both in factories and in the countryside, people in precarious economic situations, restless characters ..., they are in a worse situation in the face of a disease. We have come to recognize the importance of the personality, the constitutional peculiarity, but also its position in front of the world and external conditions of its life in the disease. The disease always develops in the course of a life replete with history; it always has multiple roots, both internal and external, the same in the somatic as in the psychic sphere and in the personal and social networks. Health and illness should not be interpreted only by their biological references, but also by their personal references.

The transformation from healthy to sick, either unforeseen or very slow, is linked to a general commotion, derived from the more or less conscious experience of suffering, knowledge of the diagnosis

Table 2. Different prognostics according to the different guides on the indicated time of rest in a sportsman with pericarditis.

\begin{tabular}{|c|l|}
\hline Prognostics & Different advices or guides [17-23] \\
\hline 1 & $\begin{array}{l}\text { - "In case of acute pericarditis, the subject must totally suspend the } \\
\text { sport activity. The return to the sport practice will require the total } \\
\text { documentation of the healing and not before } 6 \text { months of this." }\end{array}$ \\
\hline 2 & $\begin{array}{l}\text {-"The athletes will avoid competitive sports until } 6 \text { months after the } \\
\text { resolution of pericarditis." }\end{array}$ \\
\hline 3 & $\begin{array}{l}- \text { "To rest in bed while pain and fever persist. Salicylates will be } \\
\text { administered for a minimum of } 2 \text { weeks." }\end{array}$ \\
\hline 4 & $\begin{array}{l}\text { " "To rest in bed or armchair while pain and fever persist." } \\
- \text { "During acute pericarditis, participation in athletics is contraindicated. } \\
\text { Back to competition is allowed after there is no evidence of active disease. } \\
\text { This is confirmed by the absence of effusion on echocardiography and } \\
\text { the normalization of serum markers of inflammation." }\end{array}$ \\
\hline 5 & $\begin{array}{l}- \text { "Athletes with pericarditis, regardless of the etiology, should not } \\
\text { participate in competitive sports during the acute phase. Such athletes } \\
\text { can return to full activity when there is evidence that the disease is not } \\
\text { active, including absence of effusion by echocardiography, and when the } \\
\text { serum markers of inflammation have normalized." }\end{array}$ \\
\hline 6 &
\end{tabular}

and interpretation of its meaning. The functional disturbances become, without clear boundaries, organic, more durable, and often irreversible, demonstrable in the autopsy. Just as functional disturbance leads to organic injury, it can cause that. There is a circle from the functional to the organic and again to the functional. The more frequent and serious the functional disturbances, the more you can count on an organic defect. How the illness proceeds, what it means for the patient depends not only on the "disease", but essentially on the patient himself, on his position and his situation in life. Each patient does not "have" only "his illness"; he himself and his destiny "form" it. A clinical history is at the same time a story of a lifetime [24,25].

\section{The biomedical and biopsychosocial models of disease prognosis}

The difference between the biomedical model and the biopsychosocial model of prognosis is like the difference between an interview of a person that is recorded in a video or read in a book, and that which occurs live. When we see a person in a video or read a story in a book, we realize that what we can know or learn from that person is limited to what appears in the video or book; the printed image or narration of the person is the only source of information. The biomedical model imposes the same limitation on the assessment of the prognosis of the disease. The limitation of the video or the book is technical that of the biomedical model is conceptual. In medicine, the clinical definition of the disease and its repercussions on prognosis, literally depend on how we investigate or ask the patient [26-28].

The identification and management of the physical signs and symptoms of the diseases has improved, but the psychosocial burden is often not recognized and neglected [29]. In this way, the psychosocial dimensions of the diseases are often overlooked when considering medical care and disease prognosis, despite its relative importance [30]. The topics or questions that interest the patient are not easily known, and can be presented by symbols, as does the arrangement of the notes in a musical score; as a "mysterious constellation".

The disease is unique to each individual, and so the forecast is both a "science" and an "art". Formerly, in medicine, the lack of effective diagnostic or therapeutic methods made prognosis the most important competence, and of utmost relevance to relay to a patient. Hippocrates (460 BC to $370 \mathrm{BC}$ ) described prognosis as a two-dimensional construction: "quoad vitam" (predictions about survival and life expectancy) and "quoad sanationem" (predictions about healing and restoration of function). As such, the forecast can be seen as a science (predict) and an art (prediction). The way we objectively change the subjectivity of the "art of forecasting" is to contextualize the judgment; individualize and deepen to the maximum in each patient $[5,6,31]$.

In order to determine prognosis, which means to predict the outcome of a patient's illness, one must understand what make the illness unique for each individual. It is often very difficult to comment on a patient's prognosis because of the many unknown contributing factors, but the doctor should attempt to do so [32].

\section{How to establish the prognosis?}

Predicting the future is a difficult task if you do not have elements of support beyond common sense and chance. The clinical experience, the epidemiological information and the statistical probability are elements to establish a good prognosis and to minimize the uncertainty [2]. It has been said the prediction about the evolution of a patient and the final result of the disease can only be done reliably through a serious statistical study that associates the prognosis with certain 
symptoms or clinical signs. Thus, prospective cohort studies provide valuable evidence to determine the prognosis of our patients. Based on statistics and probability, indices, survival curves and prognosis scores are established, with the intention of having an objective and neutral description of reality. But this attempt to be subjective, makes us really subjective, by taking group data for individual cases. Therefore, it should be done the other way around: the more we contextualize and individualize, the more objectives we will be in that patient. In this way, the Medical Humanities are tools that can help to develop reflexivity to GPs with respect to forecasting practices [10].

\section{What is the best way to estimate the prognosis of different outcomes for an individual?}

The patient's prognosis is determined by something other than the diagnosis of the disease. We have to understand that the prognosis can be very variable in people with the same particular diagnosis (Figure 1).

The forecast is concerned with improving the usefulness of future probable outcome measures. To adequately model an individual's prognosis, the full range of relevant information available, both clinical and non-clinical, must be used. In the biopsychosocial model, this appears as an interaction of the biomedical with the psychosocial and contextual factors in order to determine the results. In this way, a medical model focused on prognosis, instead of focusing on diagnosis, offers an alternative starting point, with a broader incorporation of relevant factors for patient outcomes (Table 3).

Table 3. Taking into account the global context to be able to make the prognosis.

\begin{tabular}{|c|c|c|}
\hline & Psychosocial factors & Examples \\
\hline Disease course & $\begin{array}{l}\text {-The course of the disease is } \\
\text { influenced by the personal, } \\
\text { contextual, economic, } \\
\text { and social psychosocial } \\
\text { factors that concur (family, } \\
\text { colleagues, teachers, media, } \\
\text { social expectations, social } \\
\text { demands, culture, etc.) } \\
\text {-Patterns of "sick role" } \\
\text { are similar within families } \\
\text { (between children and } \\
\text { parents...) } \\
\text {-Dysfunctional family } \\
\text { functioning can be both the } \\
\text { cause and the consequence } \\
\text { of the family member's } \\
\text { illness }\end{array}$ & $\begin{array}{l}\text { - Abdominal pain in } \\
\text { children, headaches or } \\
\text { lumbago, in families whose } \\
\text { parents have suffered from } \\
\text { abdominal pain, headaches } \\
\text { or back pain. They are } \\
\text { families concerned about } \\
\text { the abdomen or back, and } \\
\text { they have had similar pain } \\
\text { problems previously in } \\
\text { another family member } \\
\text { - Depression often } \\
\text { complicates the recovery of } \\
\text { cardio-vascular problems }\end{array}$ \\
\hline $\begin{array}{l}\text { Severity and prognosis of } \\
\text { the disease }\end{array}$ & $\begin{array}{l}\text { The severity and prognosis } \\
\text { of the illness can be } \\
\text { predicted more accurately } \\
\text { from the loss of individual } \\
\text { and family roles and } \\
\text { activities, and from the loss } \\
\text { of roles, social activities and } \\
\text { economic level, than from } \\
\text { the clinical }\end{array}$ & $\begin{array}{l}\text {-F. T., } 61 \text { years old, presents } \\
\text { heart failure secondary to } \\
\text { alcoholic cardiomyopathy. } \\
\text { He is separated, he lives } \\
\text { only by maintaining } \\
\text { conflicting relationships with } \\
\text { his ex-wife and children; } \\
\text { there are economic problems } \\
\text { that force you to work even } \\
\text { when your clinic makes } \\
\text { it physically impossible; } \\
\text { continues drinking ... } \\
\text { Despite the best possible } \\
\text { cardiological treatment, its } \\
\text { contextual situation marks a } \\
\text { severity and prognosis even } \\
\text { worse than that of isolated } \\
\text { pathology }\end{array}$ \\
\hline
\end{tabular}

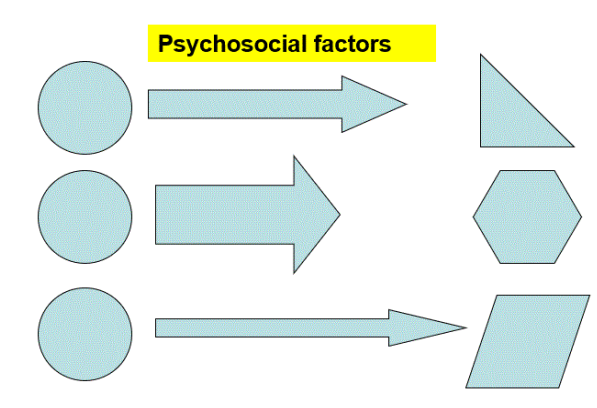

Same biological datasame diagnostics

\section{Different prognosis}

Figure 1. The prognosis of diseases depends more on psychosocial factors that of biomedical factors.

\section{Conclusion}

In our clinical case, despite the best possible cardiological treatment, patient contextual situation marks a prognosis different from what could have been done based on pathology isolated from the context. Contextual factors may be of value when assessing prognosis, irrespective of the pathology or the symptoms. Clinicians often think in terms of prognosis, especially the GPs who may start by judging if the patient is going to get better or not. Decisions about individual patients in general medicine are available based on likely prognosis [1,7].

Medical science avoids issues related to contextual judgment, the particular, the personal, and is exclusively abstract and statistical. It was Hippocrates who introduced the historical concept of disease, the idea that diseases follow a course, from their first signs to their climax or crisis, and then to their fatal or happy result. To delve into the true clinical history, we must listen to stories and contextualize the data; that is, to individualize and have a biopsychosocial vision. Only when the family doctor knows the "who" and the "where" of a patient ("who" he is and "where" he is) can he establish the "what" ("what" will happen to him); That's when you can establish a real forecast for a real individual in a particular context. [33].

GPs are able to understand the prognosis and full impact of the disease (neurological, cardiologic, etc.) and assess the prognosis, course and severity in a specific individual, without having "protocols" for each health problem in each patient. What do family doctors use to target the breadth of the clinic? How do they manage to find the middle of the clinic, without apparent reference points, in such concrete data? The course of the disease is influenced by the concurrent psychosocial factors; the severity and prognosis of the disease can be predicted more accurately from the loss of social and family roles and activities than from the biologic pathology [27]. For the family doctor, the same problem takes different forms according to its context background. There are different prognoses of the same symptom or disease according to contexts [34]. The prognosis of diseases depends more on psychosocial factors that of biomedical factors. Table 3 shows the psychosocial factors in the course and in the severity and prognosis of the disease and exposes some examples [27].

Due to this fundamental importance of prognosis in medical practice, it is recommended that GPs develop appropriate attitudes, skills and knowledge related to the formulation and communication of prognosis. Prognosis is a lost competence that must be recovered 
and placed in its rightful place. It is suggested to move from a model of medicine focused on diagnosis to a more useful one, focused on prognosis [5,35]. Conducting further studies on the validity of prognostic tools, including biopsychosocial factors to ensure their clinical value, is an important priority [36].

\section{References}

1. Croft P, Altman DG, Deeks JJ, Dunn KM, Hay AD, et al. (2015) The science of clinical practice: Disease diagnosis or patient prognosis? Evidence about "what is likely to happen" should shape clinical practice. BMC Med 13: 20. [Crossref]

2. Pimentel-Nieto D, Morales-Carmona F (2010) Medicina basada en la evidencia. Intención clínica: Pronóstico. Perinatol Reprod Hum 24: 202-206.

3. Bail K (2008) Patient and professional dissatisfaction: A literature review of prognosis communication related to hospital settings. Contemp Nurse 29: 135-146.

4. Maida V, Cheon PM (2014) Prognosis: The "missing link" within the CanMEDS competency framework. BMC Med Educ 14: 93. [Crossref]

5. Yeung H, Cheon PM, Maida V (2015) The lost competency: CanMEDS-Family Medicine and prognosis. Can Fam Physician 61: 748-750. [Crossref]

6. Díaz Novás J, Gallego Machado BR (2004) El pronóstico. Rev Cubana Med Gen Integr 20.

7. Mallen CD, Peat G, Thomas E, Wathall S, Whitehurst T, et al. (2006) The assessment of the prognosis of musculoskeletal conditions in older adults presenting to general practice: a research protocol. BMC Musculoskelet Disord 7: 84. [Crossref]

8. Wray CM, Loo LK (2015) The diagnosis, prognosis, and treatment of medical uncertainty. J Grad Med Educ 7: 523-527. [Crossref]

9. Turabián JL, Pérez Franco B (2012) The symptoms in family medicine are not symptoms of disease, they are symptoms of life. Aten Primaria 44: 232-236. [Crossref]

10. Bernegger G, Musalek M, Rehmann-Sutter C (2012) An alternative view on the task of prognosis. Crit Rev Oncol Hematol 84: S17-S24. [Crossref]

11. Hilden J, Habbema DF (1987) Prognosis in medicine: An analysis of its meaning and roles. Theor Med 8: 349-365. [Crossref]

12. Rahman A, Liu D (2011) Pericarditis: Clinical features and management. Aust Fam Physician 40: 791-796. [Crossref]

13. LeWinter MM (2014) Clinical practice. Acute pericarditis. N Engl J Med 371: 24102416. [Crossref]

14. Boraita PA, Baño RA, Berrazueta FJR, Lamiel AR, Luengo FE, et al. (2000) Clinical practice guidelines of the Spanish Society of Cardiology for physical activity in patients with cardiac disease. Rev Esp Cardiol 53: 684-726.

15. Reibis R, Kühl U, Salzwedel A, Rasawieh M, Eichler S, et al. (2017) Return to work in heart failure patients with suspected viral myocarditis. SAGE Open Med 5: 978. [Crossref]

16. Lawless CE (2009) Return-to-play decisions in athletes with cardiac conditions. Phys Sportsmed 37: 80-91. [Crossref]

17. Ortega García-Pinilla R (1992) Medicine of physical exercise and sports for health care. Díaz de Santo, Madrid.
18. Pelliccia A, Fagard R, Bjørnstad HH, Anastassakis A, Arbustini E, et al. (2005) Recommendations for competitive sports participation in athletes with cardiovascular disease. A consensus document from the study group of sports cardiology of the Working Group of Cardiac Rehabilitation and Exercise Physiology and the Working Group of Myocardial and Pericardial Diseases of the European Society of Cardiology. Eur Heart J 26: 1422-1445.

19. Arís FA, Martos FR, Sagristá SJ, Ribera CJM (1997) Management of the patient with acute and chronic pericarditis. In: Clinical update guides in cardiology aimed at primary care. Spanish Society of Cardiology, Madrid.

20. Tingle LE, Molina D, Calvert CW (2007) Acute pericarditis. Am Fam Physician 76 1509-1514. [Crossref]

21. Sagristá SJ, Almenar BL, Ferrer JÁ, Bardají RA, Bosch GX, et al. (2000) Guías de práctica clínica de la Sociedad Española de Cardiología en patología pericárdica. Rev Esp Cardiol 53: 394-412.

22. Seidenberg PH, Haynes J (2006) Pericarditis: Diagnosis, management, and return to play. Curr Sports Med Rep 5: 74-79. [Crossref]

23. Maron BJ, Zipes DP (2005) Bethesda conference report. $36^{\text {th }}$ Bethesda conference: Eligibility recommendations for competitive athletes with cardiovascular abnormalities. $J$ Am Coll Cardiol 45.

24. Siebeck R (1957) Medicina en movimiento. Editorial Científico-Médica, Barcelona.

25. Turk DC, Kerns RD (1985) A biopsychosocial approach to illness and family: Neurological diseases across the life span. In: Health, illness, and families. A life-span perspective. John Wiley and Sons, New York.

26. Turabián JL, Pérez Franco B (2006) The specific framework of clinical practice in family medicine: Implications for practice and training. Aten Primaria 38: 349-352.

27. Turabián JL, Perez Franco B (2008) Do family doctors seem like turtles? Semergen 34: 373-374.

28. Engel GL (1990) The essence of the biopsychosocial model: From 17th to 20th century science. In: Balner H, DeVries MJ, Engel GL, Goodkin IK, LeShan L, et al. A new medical model: A challenge for biomedicine? Swets \& Zeitlinger B.V, Amsterdam, Netherlands.

29. Turner J, Kelly B (2000) Emotional dimensions of chronic disease. West J Med 172 124-128. [Crossref]

30. Turabián JL, Pérez-Franco B (2014) Journey to what is essentially invisible: Psychosocial aspects of disease. Semergen 40: 65-72. [Crossref]

31. Lim LS, Feldman BM (2013) The risky business of studying prognosis. J Rheumatol 40: 9-15. [Crossref]

32. Morgan WJ, Engel GL (1969) The clinical approach to the patient. WB Saunders Company, London.

33. Turabian JL, Franco BP (2017) Responses to clinical questions: Specialist-based medicine $v s$. reasonable clinic in family medicine. Integr J Glob Health 1: 1.

34. Turabian JL (2017) For decision-making in family medicine context is the final arbiter. J Gen Pract (Los Angel) 5: e117.

35. Voineskos G, Pollock BG (1980) Concepts and practice of prognosis in psychiatry. Can J Psychiatry 25: 619-625. [Crossref]

36. Stevinson C, Preston N, Todd C, Cancer Experiences Collaborative (CECo) (2010) Defining priorities in prognostication research: Results of a consensus workshop. Palliat Med 24: 462-468.

Copyright: (C2018 Turabian JL. This is an open-access article distributed under the terms of the Creative Commons Attribution License, which permits unrestricted use, distribution, and reproduction in any medium, provided the original author and source are credited. 